\title{
A Comparative Study of Hernioplasty Done Under Local And Spinal Anaesthesia in A Tertiary Care Centre
}

\author{
Najim Hiquemat ${ }^{1}$,Hussain Ahmed $^{2 *}$ \\ ${ }^{1}$ Resident Surgeon, Department Of General Surgery, Guwahati Medical College And Hospital, Guwahati; \\ ${ }^{2}$ Associate Professor,Department Of General Surgery, Guwahati Medical College And Hospital,
}

\begin{abstract}
:
Background: Surgical repair of inguinal hernia is one of the most commonly performed operations in general surgery worldwide. Hernia repair is commonly done under general or spinal anaesthesia but the advent of day care surgery has prompted renewned interest in the use of local anaesthesia for open hernia surgeries.

Objectives: to compare the outcome of hernia repair done under spinal and local anaesthesia in relation to intra operative and post operative events.

Materials and methods: We carried out a prospective study of 60 patients who were admitted with inguinal hernia. Patients were randomized into two groups of 30 each -the study group, group A (where local anesthesia was used) and the controll group, group B (where spinal anaesthesia was used) by lottery method. Intraoperative and post-operative parameters were noted and all the data collected was annalysed by using the "Paired Student t test".

Results: in the study, local anaesthesia was found to be associated with less operating time, less post operative pain and hypotension, less urinary retension, early discharge, faster resumption of work and less overall cost. There was no difference with respect to nausea, vomiting, wound infection, seroma formation and intra operative complications like bradycardia. However, intra operative pain was noted in a few cases operated under local anaesthesia.

Conclussion: tension free hernioplasty done under local anaesthesia is safe with very few complications ; cost effective with early return to activity and discharge, and ideal for day care surgery in regional as well as in teaching hospitals.
\end{abstract}

Keywords: local anaesthesia, spinal anaesthesia, inguinal hernia repair, Lichtenstein mesh hernioplasty.

\section{Introduction}

Hernias are amongst the oldest known ailments of mankind with the earliest references dating back to 1500 b.c. Surgery is the definitive treatment for hernia and remains one of the most commonly performed operations in general surgery worldwide. . Inguinal hernias are 9 times more common in males than in females with an overall lifetime risk of developing groin hernias being approximately $15 \%$ in males and $5 \%$ in females ${ }^{1}$. The incidence of inguinal hernia increases with age, from around 11 per 10,000 persons aged between $16-24$ to around 200 per 10,000 persons aged 75 years and above ${ }^{2}$. A globally aging population means that the demand for surgical services for hernia is ever increasing. The technical aspect of hernia surgery has evolved over time. Numerous techniques have been described to date for the repair of inguinal hernia- both open and laparoscopic. Open method of inguinal hernia repair remains popular worldwide. It can be performed under all types of anesthesia- general ,spinal, epidural and local. Open repair under local anesthesia has been reported to be both safe and economic. However, its use is not wide spread despite benefits observed by several centers of excellence worldwide ${ }^{3}$.

With the introduction of "Day care Surgery" for inguinal hernia repair, local anesthesia has a pivotal role as it reduces the cost and duration of hospital stay. Short stay surgery not only relieves the hospital waiting period but also represents an economic advantage and has social benefits for the patient. With around 20 million groin hernia repairs performed globally every year ${ }^{4}$, even a small variation in practice pattern can have huge socio- economic implications. The objective of this work was to compare the safety, effectiveness, post operative complications, hospital stay and post operative recovery in hernia surgery done under local anaesthesia versus spinal anaesthesia and to study if hernioplasty under local anesthesia is an acceptable alternative to conventional hernioplasty using spinal anesthesia.

\section{Materials And Methods}

We carried out a prospective study of 60 male patients who were admitted with inguinal hernia in surgical wards of Gauhati Medical College Hospital between july 2014 and june 2015.

Inclusion criteria included: 1.All patients admitted and operated in surgical wards of GMCH with primary uncomplicated inguinal hernia on elective basis 2.Patients aged above 12 years 3.Patients with unilateral hernia 
Exclusion criteria included: 1.Age less than 12 years 2.Complicated hernias 3.Patients with recurrent hernia 4.Patients with bilateral hernia 5. Patients with psychiatric problems 6. Patients with medical illness like uncontrolled DM, HTN, COPD, Obesity, BPH 7.Bleeding disorders 8. Patient with contraindication to local or spinal anesthesia 9. Patient refusal After admission to the hospital detailed history was taken and thorough clinical examination was done. Pre-operative routine investigations like hemoglobin, total leucocyte count, differential leucocyte count, random blood sugar, renal function tests, chest X-ray and electrocardiogram were done in all case. Patients were explained about the surgery and the type of anesthesia and also about the advantage \& disadvantage of each type of anesthesia. They were explained about benefits from early mobilization, early discharge \& socio economic benefits of short stay surgery. Written consent was taken for all the cases. Patients were randomized either to study group, group A (where local anesthesia was used) or controll group, group B (where spinal anaesthesia was used ) by lottery method.

\section{Technique of administration of local anesthesia used:}

The skin was infiltrated $2 \mathrm{~cm}$ above and medial to the anterior superior spine, deep to the external oblique aponeurosis with approximately $10 \mathrm{ml}$ of solution of $0.5 \%$ in a fan shaped manner to block the iliohypogastric and ilioinguinal nerves, and the last two intercostals nerves (fig 1). Mid inguinal point was infiltrated with another $10 \mathrm{ml}$ of $0.5 \%$ lignocaine deep to the external oblique to block the genital branch of the genito-femoral nerve. The pubic tubercle area was infiltrated with 5 to $10 \mathrm{ml}$ of $0.5 \%$ lignocaine to block the contralateral nerve fibres. An additional 5 to $10 \mathrm{ml}$ of solution was injected subcutaneously below the inguinal ligament, lateral to the femoral artery to block the overlapping branches of the external femoral cutaneous and the femoral branch of the genitor femoral nerves. Approximately $5 \mathrm{ml}$ of solution was used to infiltrate the epidermis at the exact site of the incision (Fig2). Upon reaching the external oblique aponeurosis $5 \mathrm{ml}$ of solution was deposited in the subaponeurotic space prior to clearing this layer. In case of indirect hernia, 1-2ml of solution was injected about the neck of the hernial sac before it was opened. In case of direct hernia , 1-2ml of solution was placed in the rectus fascia at the site of relaxing incision. Further anaesthetic administration was done if patient felt pain during the procedure.

Tension free Lichtenstein hernioplasty was done in both groups. Material used for hernioplasty was Polypropylene Prosthetic mesh (Fig3). The following parameters are studied in both local anaesthetic \& spinal anaesthetic group-1.Time taken for the procedure: this included time taken from giving anaesthesia to completion of surgery. 2. Complications during time of surgery like bradycardia(heart rate $<60 / \mathrm{min}$ ), hypotension (systolic BP $<90 \mathrm{~mm}$ of $\mathrm{Hg}$ in supine position), pain during surgery, \& cardio respiratory complications during surgery 3. Ambulation after $1 \mathrm{hr}$ of surgery 4. Post operative complications like nausea \& vomiting, difficulty in voiding \& urinary retention, headache, post operative pain 5 . Complications related to the operative procedure-seroma, haematoma, scrotal edema, ischemic orchitis, infection etc 6. Duration of hospital stay 7.Time needed for return to normal activity 8. Cost of anesthetic medication 9. Assessment during follow up for chronic groin pain, wound infection and recurance.

All the data collected was annalysed by using the "Paired Student $t$ test".

\section{Results And Observations}

In the present study, the age varies from 18 years to 75 years. The highest incidence of inguinal hernia was seen in the age group 51 to 60 years $(33.33 \%$ ), followed by the age groups 21-30 and 41-50 (both 16.67\%). Only males patients were included in our study. The incidence of indirect inguinal hernia was 40(66.67\%) and that of direct inguinal hernia was $20(33.33 \%)$. There were no cases of pantaloon or mixed hernia in the present study. 38 cases of hernia were on the right side and 22 on the left. Cases of bilateral inguinal hernia were not included. In our study the mean operating time for the SA Group was $64.8 \pm 10.12$ minutes \& in LA group, it was 52.06 \pm 6.78 minutes. The difference was statistically significant $(\mathrm{p}<0.0005))$.

Table 1: duration of the operative procedure:

\begin{tabular}{|c|c|c|c|}
\hline $\begin{array}{c}\text { Time taken for the } \\
\text { operation (in minutes) }\end{array}$ & $\begin{array}{c}\text { Number of patients in LA } \\
\text { group }\end{array}$ & $\begin{array}{c}\text { Number of patients in } \\
\text { the SA group }\end{array}$ & $\begin{array}{c}\text { Number of patients in } \\
\text { both groups }\end{array}$ \\
\hline $40-50$ & 15 & 5 & 20 \\
\hline $51-60$ & 10 & 3 & 13 \\
\hline $61-70$ & 5 & 10 & 15 \\
\hline $71-80$ & - & 12 & 12 \\
\hline
\end{tabular}

In the present study none of the patients experienced intra operative pain while under spinal anaesthesia. In the LA Group ,9(30\%) people had mild discomfort but not pain during surgery while $6(20 \%)$ patients experienced mild pain(VAS 1-3) and 4(13.33\%) patients experienced moderate pain(VAS 4-7) during 
surgery. The mean VAS for the LA Group was $1.14 \pm 1.92$ and the difference between the two groups was statistically significant $(\mathrm{p}=0.0012)$.

Table 2: intra -operative pain assessment

\begin{tabular}{|c|c|c|}
\hline Intra Operative Pain Score & La Group (Cases/\%) & Sa Group (Cases/\%) \\
\hline No Pain & $20(66.66 \%)$ & $30(100 \%)$ \\
\hline $\begin{array}{c}\text { Mild Pain } \\
\text { Vas (1-3) }\end{array}$ & $6(20 \%)$ & 0 \\
\hline $\begin{array}{c}\text { Moderate Pain } \\
\text { Vas (4- } 7)\end{array}$ & $4(13.33 \%)$ & 0 \\
\hline $\begin{array}{c}\text { Severe Pain } \\
\text { Vas(8-10) }\end{array}$ & 0 & 0 \\
\hline
\end{tabular}

Bradycardia was noted in $2(6.67 \%)$ patients of LA group \& 4(13.33\%) of SA group. The difference was not significant $(\mathrm{p}=0.1949)$. Hypotension was seen in $9(30 \%)$ patients of SA group and 1 patient in LA group $(3.33 \%)$. The difference was significant $(\mathrm{p}=0.0055)$.

In the LA Group,5(16.67\%) people had no pain after surgery, while 19(63.33\%) patients experienced mild pain and 6(20\%) patients experienced moderate pain after surgery. None had severe pain. In the SA Group,2(6.67\%) people had no pain after surgery, while $10(33.33 \%)$ patients experienced mild pain and 17(56.67\%) patients experienced moderate pain after surgery. 1 (3.33\%) patient had severe pain. Mean VAS score was 2.23 (mild pain) for the LA Group and for the SA Group mean VAS score was 4 (moderate pain). The difference between the two groups was found to be statistically significant. $(\mathrm{p}=0.00026)$.

Table 3: Post-operative pain scores(VAS)

\begin{tabular}{|c|c|c|c|}
\hline Post Operative Pain & $\begin{array}{c}\text { La Group } \\
(\text { Cases \%) }\end{array}$ & $\begin{array}{c}\text { Sa Group } \\
(\text { Cases / \%) }\end{array}$ & $\begin{array}{c}\text { Total } \\
(\text { Cases / \%) }\end{array}$ \\
\hline No Pain & $5(16.67 \%)$ & $2(6.67 \%)$ & $7(11.67 \%)$ \\
\hline $\begin{array}{c}\text { Mild Pain } \\
\text { Vas (1-3) }\end{array}$ & $19(63.33 \%)$ & $10(33.33 \%)$ & $29(48.33 \%)$ \\
\hline $\begin{array}{c}\text { Moderate Pain } \\
\text { Vas (4-7) }\end{array}$ & $6(20 \%)$ & $17(56.67 \%)$ & $23(38.33 \%)$ \\
\hline $\begin{array}{c}\text { Severe Pain } \\
\text { Vas(8-10) }\end{array}$ & 0 & $1(3.33 \%)$ & $1(1.67 \%)$ \\
\hline Total & $30(100 \%)$ & $30(100 \%)$ & $60(100 \%)$ \\
\hline
\end{tabular}

3 patients in SA group $(10 \%) \& 2$ patients $(6.67 \%)$ in LA group experienced nausea \& vomiting. The difference was not statistically significant. $(\mathrm{p}=0.64)$.In the present study none of the the patients who underwent hernioplasty under local anesthesia had post operative urinary retention, while $6(20 \%)$ of patients operated under spinal anesthesia had post operative retention and required catheterisation. This was statistically significant. $(\mathrm{p}=0.0098) .25$ patients $(83.33 \%)$ in LA group were ambulant at the end of $1 \mathrm{hr} \&$ none in SAB group. $(\mathrm{p}=0.001)$. Post operative headache seen in $3(10 \%)$ patients in SA group \& none of the patient of LA group. $(\mathrm{p}=0.0756)$. The difference was not significant. In the present study, wound infection occurred in 1 out of 30 inguinal hernia repair done under local anesthesia and 1 out of 30 inguinal hernia repairs done under spinal anesthesia. 2(6.67\%) patients in LA group and 1(3.33\%) patient in SA group developed seroma. The difference was not significant. $(\mathrm{p}=0.55)$. None of the patients in either group developed hematoma. In present study scrotal oedema was present in $1(3.33 \%)$ patient of LAgroup and $3(10 \%)$ patients of SAgroup . The difference was not significant. $(\mathrm{p}=0.3003)$. Overall hernioplasty under spinal anesthesia is associated with more complication than hernioplasty under local anesthesia.

Table 4: post operative observations

\begin{tabular}{|l|l|l|l|l|}
\hline Complications & LA Group & SA Group & P value & Significance \\
\hline Vomiting & $6.67 \%$ & $10 \%$ & 0.64 & Not significant \\
\hline Urinary retention & 0 & $20 \%$ & 0.0098 & significant \\
\hline headache & 0 & $10 \%$ & 0.0756 & Not significant \\
\hline seroma & $3.33 \%$ & $6.67 \%$ & 0.55 & Not significant \\
\hline Wound infection & $3.33 \%$ & $3.33 \%$ & - & - \\
\hline Ambulation after 1 hour & $83.33 \%$ & 0 & 0.001 & significant \\
\hline Scrotal edema & $3.33 \%$ & $10 \%$ & 0.3003 & Not significant \\
\hline
\end{tabular}

In the present study the mean hospital stay in the SA group was $2.73 \pm 0.90$ days and the mean stay in the LA group was $1.73 \pm 0.87$ days. It was statistically significantly less in group A as compared to group B. (p $<0.001$ ). Mean time taken to resume work in LA group was $5.47 \pm 1.52$ days and $6.97 \pm 2$ days in SA group. It 
was statistically significant $(\mathrm{P}<0.001)$. In our study the patients who came for follow up at 7 days, 1 month,and 6 months, no case of chronic groin pain or recurrence was found in both LA Group and SA Group. 6 patients did not turn up after the first follow up. Ideally patients should have followed for a longer period but this was not possible due to the limited study period.

Table 5: Time taken for resumption of normal work

\begin{tabular}{|c|c|c|}
\hline Time taken to resume normal work & LA Group & SA Group \\
\hline 2 days & 1 & - \\
\hline 3 days & 2 & 2 \\
\hline 4 days & 5 & 4 \\
\hline 5 days & 6 & 6 \\
\hline 6 days & 8 & 12 \\
\hline 7 days & 7 & 6 \\
\hline$>7$ days & 1 & \\
\hline
\end{tabular}

\section{Discussion}

Duration of procedure: The time was calculated in both the groups from the time of anaesthesia till dressing. In SA group the mean operating time was $64.8 \pm 10.12$ minutes \& in LA group 52.06 \pm 6.78 minutes. The difference was statistically significant $(\mathrm{p}<0.0005)$. Pradeep Goyal et $\mathrm{al}^{5}(2014)$ reported mean operative time of $42.8 \pm 8.6$ minutes for cases operated under local anesthesis and $64.45 \pm 13.7$ minutes for those operated under spinal anesthesia. Ashok Kumar et $\mathrm{al}^{6}$ (2013) reported the average operative time taken in hernia repair as 39.84 minutes and 56.36 minutes in local and spinal anaesthesia respectively. Suthat Aphykunchorn et $\mathrm{al}^{7}$ reported that the mean of operating time was significantly lower in the local anesthesia group $(\mathrm{p}=0.02)$.

Intra operative pain: In the present study none of the patients experienced pain while under spinal anaesthesia. In the LA Group,9(30\%) people had mild discomfort but not pain during surgery while $4(13.33 \%)$ patients experienced mild pain and $2(6.67 \%)$ patients experienced moderate pain during surgery. The mean VAS for the LA Group was $1.14 \pm 1.92$ and the difference between the two groups was statistically significant $(\mathrm{p}=0.0012)$. Jihad odeh et $\mathrm{al}^{8}$ ( 2011) reported that among patients operated under local anesthesia five patients (7\%) experienced mild discomfort which was tolerable, but no actual pain. Four patients $(5.5 \%)$ had slight pain which settled with further sedation and local anesthetic infiltration. Jignesh Jethva et $\mathrm{al}^{9}(2015)$ repoted that In local anesthesia group 7 patients $(14 \%)$ had intra operative discomfort in form of pain and none in the spinal anesthesia group. David v Young et $\mathrm{al}^{10}(1987)$ reported that $13 \%$ of patients operated under local anesthesia had pain during the surgery compared to $7 \%$ for those under spinal anesthesia.

Intra-operative hypotention and bradycardia: Bradycardia was noted in $2(6.67 \%)$ patients of LA group \& 4(13.33\%) of SA group.They were treated with injection atropine $1 \mathrm{mg}$ iv \& heart rate is converted into normal rhythm in $3(10 \%)$ patients. The difference was not significant $(\mathrm{p}=0.1949)$. Hypotension was seen in 9 $(30 \%)$ patients of SA group and were treated with cyrstalloids \& vasopressors. One patient in LA group $(3.33 \%)$ experienced hypotension. The difference was significant $(\mathrm{p}=0.0055)$. Khurram Niaz et $\mathrm{al}^{11}$ (2009) reported a $2 \%$ rate of hypotension in the SA Group and none in the LA Group.

Post operative pain: Post operatively the patients were questioned about pain \& assessed for need for analgesia at 6 hours.. In the LA Group,5(16.67\%) people had no pain after surgery, while 19(63.33\%) patients experienced mild pain and 6(20\%) patients experienced moderate pain during surgery. None had severe pain. Mean VAS score was 2.23 (mild pain).In the SA Group,2(6.67\%) people had no pain after surgery, while $10(33.33 \%)$ patients experienced mild pain and $17(56.67 \%)$ patients experienced moderate pain during surgery. $1(3.33 \%)$ patient had severe pain. Mean VAS score was 4 (moderate pain). The difference was significant $(\mathrm{p}=0.00026)$. Song D et $\mathrm{al}^{12}(2000)$ showed that VAS scores were $15 \pm 1.4$ in patients operated under local anaesthesia compared to $34 \pm 3.2$ in patients operated under spinal anaesthesia. Post operative pain was statistically less in patients operated under local anaesthesia. Nordin et $\mathrm{al}^{13}$ (2003) reported that patients receiving local anesthesia had significantly less pain ostoperatively than the other groups. Opiates were given to only 8 percent of patients receiving local anesthesia, compared with 22 percent of patients receiving regional anesthesia and 34 percent of patients receiving general anesthesia. R.N. van Veen et al ${ }^{14}(2008)$ reported showed that patients operated under local anesthesia had signifi cant less pain shortly after surgery $(\mathrm{p}=0.021)$. Pradeep Goyal et $\mathrm{al}^{5}$ (january 2014) reported that in LA groupA,68\% patients felt mild pain and $20 \%$ patients felt moderate pain. However in SA group B, $44 \%$ patients felt mild pain and $56 \%$ patients felt moderate pain. The difference was statistically significant. $(\mathrm{p}<0.05)$. Jignesh Jethva et $\mathrm{al}^{9}(2015)$ reported that $64 \%$ of patients of LA group had mild pain and $38 \%$ had moderate pain. None of the patients belonged to serve pain group. In SA $6 \%$ of the patients had severe pain; $22 \%$ had mild pain and $72 \%$ patients had moderate degree of pain. Mohammad Sadegh Zamani-Ranani et al ${ }^{15}$ (2015) reported tha the pain score at the 3, 6 and 12 hour periods after surgery was significantly lower in LA group $(\mathrm{P}<0.0001)$. But there was no significant difference between 
groups in pain score at the 24 hour period after surgery $(\mathrm{P}=0.24)$. Also, the LA group needed lower analgesic agents $(\mathrm{P}=0.001)$.

Nausea and vomiting: 3 patients in SAB group $(10 \%) \& 2$ patients $(6.67 \%)$ in LA group experienced nausea $\&$ vomiting. The difference was not statistically significant. $(\mathrm{p}=0.64) . \quad$ Abdul Razaque Shaikh et $\mathrm{al}^{16}$ (2012) in his study of 108 hernioplasties under local anesthesia reported that 2 patients $(1.85 \%)$ in early post-operative phase had vomiting. Jignesh jethva et $\mathrm{al}^{9}$ (2015) reported a comparative study of 100 patients( 50 under local anesthesia and 50 patients under spinal anesthesia) where no patient developed nausea or vomiting post operatively.

Urinary retension: In the present study none of the the patients who underwent hernioplasty under local anesthesia had post operative urinary retention, while $6(20 \%)$ of patients operated under spinal anesthesia had post operative retention and required catheterisation. This was statistically significant. $(\mathrm{p}=0.0098)$. Nordin et $\mathrm{al}^{13}$ (2003) reported that no patients in the local anesthesia group required catheterization for postoperative urinary problems, although this step was required in 8 percent of patients following administration of general anesthesia and in 29 percent following administration of regional anesthesia. R.N. van Veen et $\mathrm{al}^{14}(2008)$ reported that patients operated underspinal anesthesia had signifi cantly more urinary retension after surgery ( $\mathrm{p}$ $<0.001)$. Khurram Niaz et $\mathrm{al}^{11}$ ( 2009) reported urinary retention of $16 \%$ for those operated under spinal anesthesia and none in the local anesthesia group. Abdul Razaque Shaikh et al ${ }^{16}$ (2012) reported a $0.92 \%$ incidence of urinary retention in ceses operated under local anesthesia. Ashok Kumar et al ${ }^{6}$ (2013) reported $12 \%$ incidence of hesitancy and retention of urine under spinal anaesthesia and none under local anesthesia. Pradeep Goyal et $\mathrm{al}^{5}$ (january 2014) reported that none of the patients operated under local anesthesia had urinary retention while $20 \%$ of the patients operated under sinal anesthesia had urinary retention.

Ambulation after surgery: 25 patients (83.33\%) in LA group were ambulant after $1 \mathrm{hr}$ of the surgery but none of the patients were ambulant in SA group. The difference was statistically significant. $(\mathrm{P}=0.001)$.

Post operative headache: Post operative headache seen in 3(10\%)patients in SA group \& none of the patient of LA group. David v Young et al ${ }^{10}$ (1987) reported the incidence of post operative headache to be $7 \%$ in the LA Group and $8 \%$ in the SA Group. Pradeep Goyal et $\mathrm{al}^{5}$ ( 2014) in his study of 50 hernioplasty patients did not report a single case of post operative headache.

Wound infection: In the present study, wound infection occurred in 1 out of 30 inguinal hernia repair done under local anesthesia and 1 out of 30 inguinal hernia repairs done under spinal anesthesia. Infections were treated with antibiotics and regular dressings.

Shyam Kumar Shrestha et $\mathrm{al}^{17}$ (2006) reported a superficial surgical site infection of $1.6 \%$ in inguinal hernia cases repaired under local anesthesia. Khurram Niaz et $\mathrm{al}^{11}$ ( 2009) reported a wound infection rate of $2 \%$ in local anesthesia group and 5\% in the spinal anesthesia group. Jia-Sen Gao et $\mathrm{al}^{18}$ (2009) reported a retrospective review of all 110 patients who had undergone inguinal hernia repair with mesh under local anesthesia in which no wound infection was noted. Abdul Razaque Shaikh et $\mathrm{al}^{16}(2012)$ reported that $2.7 \%$ patients in late phase had wound infection.following inguinal hernia repair under local anesthesia.

Hematoma and seroma: 2(6.67\%) patients in LA group and 1(3.33\%) patient in SA group developed seroma.In total3 $(5 \%)$ patients developed seroma. None of the patients in either group developed hematoma. George H Sakorafas et $\mathrm{al}^{19}$, 2001 in their study of 540 tension-free inguinal hernia repairs found hematoma formation requiring drainage in 2 patients and seroma in 6 patients out of 540 patients.

Scrotal oedema: In present study scrotal oedema was present in $1(3.33 \%)$ patient of LAgroup and 3 $(10 \%)$ patients of SAgroup . The difference was not significant. $(\mathrm{p}=0.3003)$. Shyam Kumar Shrestha et $\mathrm{al}^{17}$ (2006) reported a $3.1 \%$ incidence of scrotal odema following hernioplasty under local anesthesia.

Duration of hospital stay: In the present study the mean hospital stay in the SA group was $2.73 \pm 0.90$ days and the mean stay in the LA group was $1.73 \pm 0.87$ days. It was statistically significantly less in group A as compared to group B. ( $\mathrm{p}<0.05)$. The study conducted by Song D et al ${ }^{12}(2000) 14$ found that the time to discharge to be shorter after local anaesthesia (158 minutes) than after general (208 minutes) and spinal anaesthesia (308 minutes). Enzio Gianetta et $\mathrm{al}^{20}$ (2000) in his study of 146 hernioplasties done under local anesthesia found that the mean hospital stay after surgery was 1.5 days (range 3 hours-14 days). Patrick J. $\mathrm{O}^{\prime}$ Dwyer et $\mathrm{al}^{21}$, (2003) reported that total hospital stay was $3.1 \pm 0.8$ days for the LA group and 3.2 \pm 1.2 for the GA group. Abdul Razaque Shaikh et $\mathrm{al}^{16}$ (2012) in their study of 108 hernioplasties done under local anesthesia reported the mean hospital stay to be $27.27 \pm 9.91$ hours.

Time taken for resumption of normal work: Mean time taken to resume work in LA group was $5.47 \pm 1.52$ days and $6.97 \pm 2$ days in SA group. It was statistically significant $(\mathrm{P}<0.05)$. Pradeep et al ${ }^{5}$ reported that $(60 \%)$ patients in LA group resumed work after 7 days whereas most of the SA group patients took more than 7 days to resume normal activities or work. Mean time taken to resume work in LA group was 5.6 \pm 2.64 days and 7.04 \pm 3.51 days in the SA group. The study done by Teasdale et $\mathrm{al}^{22}$ (1982) on 103 patients found faster recovery after local anaesthesia as compared to general and spinal anaesthesia.

The study 
conducted by Barkerville PA et $\mathrm{al}^{23}$ (1983) showed that return to normal activity by 3rd post operative day in 49 (38\%) patients, by end of 1 week in $78 \%$ patients and by end of 2 weeks in $98 \%$ patients.

Chronic groin pain and recurrence after surgery: In our study the patients who came for follow up at 7 days, 1 month,and 6 month, no case of chronic groin pain or recurrence was found in both LA Group and SA Group. 6 patients did not turn up after the first follow up. Ideally the patients should have been followed for a longer period but this was not not possible due to the limited study period. Pradeep et $\mathrm{al}^{5}$ did not report a single case of chronic groin pain or recurrance. Khurram Niaz et $\mathrm{al}^{11}$ (2009) reported a $2 \%$ incidence of recurrance following hernioplasty under SA..

\section{Conclussion}

Though both local \& spinal anaesthesia can be used for hernia repair on short stay basis, spinal anaesthesia was found to have higher complication rates compared to local anaesthesia. There is significant increase in general complications like hypotension, bradycardia, urinary retention and headache in spinal anaesthesia. The mean operating time was much shorter with local anesthesia.We found that there was a marked reduction in postoperative pain in LA Group as compared to the SA Group. Post operative ambulation was markedly quicker with local anesthesia. The duration of hospital stay was shorter and the return to normal activity faster with local anesthesia. Overall, local anaesthesia was associated with less immediate post operative complication. No recurrences were noted during the study period. It is apparent from the study that local anesthesia is a better alternative to spinal anesthesia from short stay or day care surgery. When short stay service is implemented there will considerable savings to hospital service $\&$ to the patients.

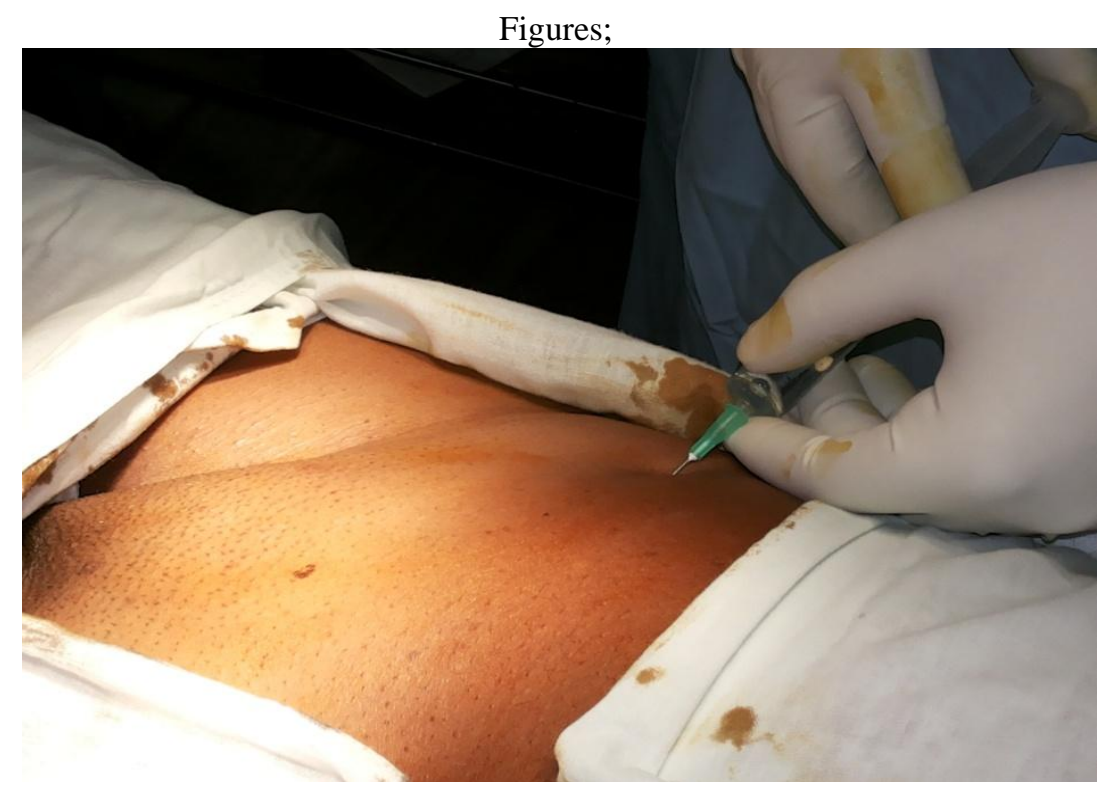

Fig1: infltration of local anesthesia

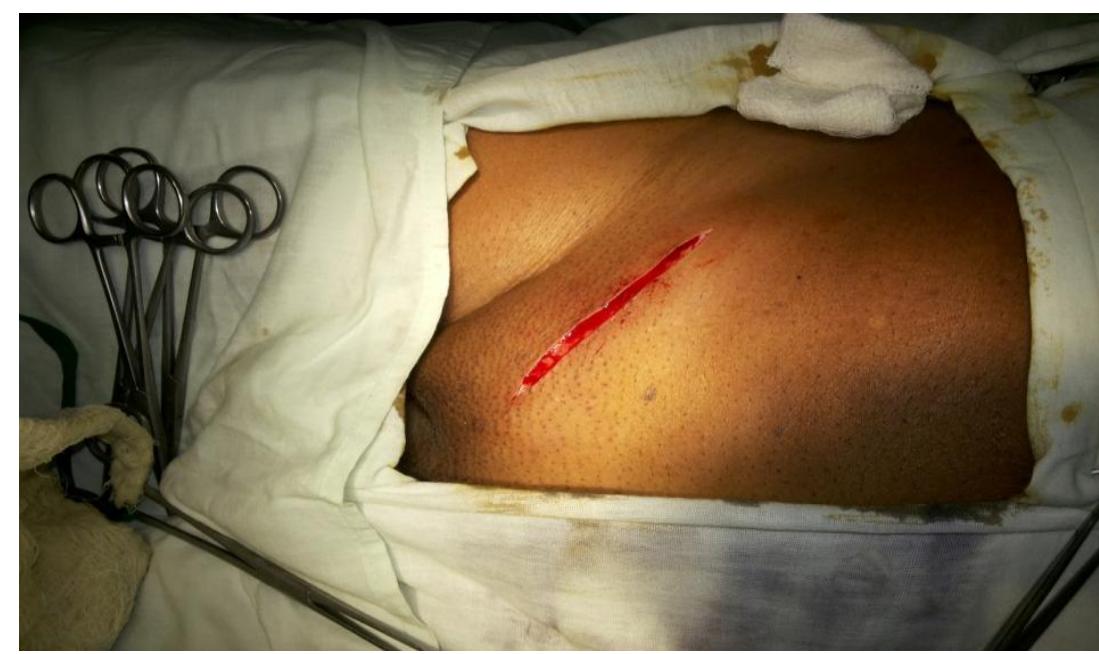

Fig 2: inguinal incision for hernioplasty 


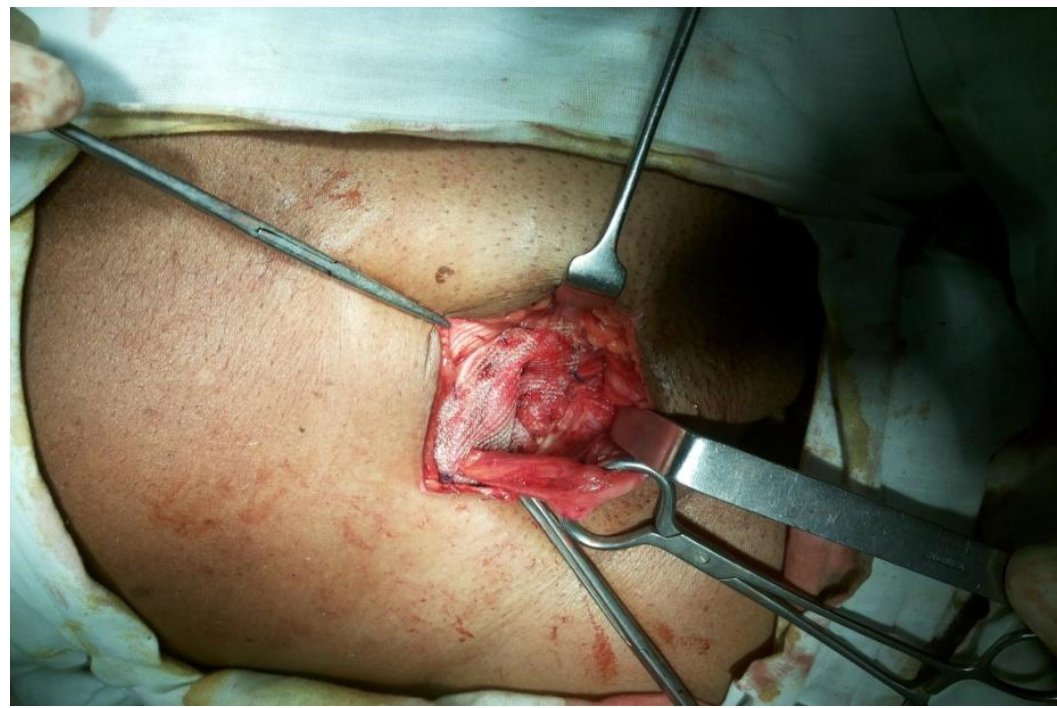

Fig3: placement of mesh

\section{Bibliography}

[1]. Micheal J. Zinner, Stanley W. Ashley; Maingot's abdominal operations, 11 th edition, p103

[2]. Chow A, Purkayastha S, Athanasiou T, Tekhia P, Darzi A. Inguinal hernia. BMJ Clin Frid 2007; 4:1-20

[3]. Abdu RA. Abbulatory herniorapphy under local anesthesia in a community hospital. AMJ SURG. 1983; 145(3):353-6

[4]. Bay Nielsen M, Kehlet H, Strand L, et al: quality assessment of 26,304 herniorrapphies in Denmark: a nationwide prospective study. Lancet.2001 Oct6;358(9288):1124-8

[5]. Pradeep Goyal et al, comparision of inguinal hernia repair under local anesthesia and spinal anesthesia. IOSR Journal of dental and Medical Sciences(IOSR-JDMS)e-ISSN:2279-0853,p-ISSN:2279-0861. Volume 13, Issue1Ver.VI. (Jan.2014),PP54-59

[6]. Ashok Kumar et al, A prospective comparitive study of Lichtenstein tension free hernioplasty under local anesthesia and spinal anesthesia, Scholars Journal Of Applied Medical Sciences(SJAMS) ISSN2320-6691 (Online) Sch J.App. Med. Sci, 2013;1(6):934936

[7]. Suthat Aphykunchorn et al, Local and spinal anesthesia in Lichtenstein tension free hernioplasty for inguinal hernia repair, Buddhachinaraj Medical Journal, Thailand, Vol.27 No1 January-April 2010

[8]. Jihad odeh et al, Inguinal herniorrhaphy under local anesthesia:outcome and tolerance among patients in Royal Medical Service, Rawal Medical Journal, 2011;36(2):120-122

[9]. Jignesh Jethva et al, Comparision of hernioplasty inder local anesthesia v/s spinal anesthesia, International Archieves Of Integrated Medicine, Vol2, Issue 5, May 2015

[10]. David v Young,Comparion of local, spinal and general anesthesia for inguinal herniorraphy. AmericanJournal of Surgery,1987.Vol 153:560-563

[11]. Khurram Niaz et al, Comparision of inguinal herniorrhaphy under local and spinal anesthesia, Pakistan Journal Of Medical Health Sciences, Vol4, Issue 3. Sept 2010

[12]. Song D et al, Recovery profiles and cost of anesthesia for outpatuent unilateral inguinal herniorrhaphy, Anesth Analg 2000; 91:876-

[13]. Nordin et al, Local, regional or general anesthesia in groin hernia repair; multicentr randomised trial. Lancet. Sept 13, 2003; $362: 853-8$

[14]. R.N. van Veen et, Spinal or local anesthesia in Lichtenstein hernia repair; a randomised controll trial; New Clinical Concepts in Inguinal Hernia; 2008, Netherlands

[15]. Mohammad Sadegh Zamani-Ranani et al, Acomparision between local and spinal anesthesia in inguinal hernia repair, International Journal Of Clinical Anesthesiology, January 2015, 3(1):1041

[16]. Abdul Razaque Shaikh et al, Inguinal mesh hernioplasty under local anesthesia, Journal Of Pakistan Medical Association, june 2012, 62:566;2012

[17]. Shyam Kumar Shrestha et al, Outcome of Lichenstein Operation: Aprospective evation of sixety four patients. NMCJ Vol.8 No 4 December 2006

[18]. Jia-Sen Gao et al, Inguinal hernia repair with tension free hernioplasty under local anesthesia, Saudi Medical Journal, Vol30, No4, 2009

[19]. George H Sakorafas et al, Open tension free repair of inguinal hernias; the Lichenstein technique; BMC Surgery2001,1:3 http://www.biomedcentral.com/1471-2482/1/3

[20]. Enzio Gianetta et al, Anterior tension free repair of recurrent inguinal hernia under local anesthesia- a 7 year experience in a teaching hospital. Annals of Surgery.2000 Jan;168(8-9);455-9

[21]. Patrick J. O’Dwyer et al, Local or general anesthesia for open hernia repair: a randomise trailAnnals of Surgery Vol237,No4,574579

[22]. Teasdale et al, A randomised controll trial to compare local with general anesthesia for short stay inguinal hernia repair. Ann R Coll Surg Engl 1982; 64:238-242

[23]. Barkerville PA et al, Day care inguinal hernia repair under local anesthesia. Ann R Coll Surg Engl 1983:65:224-5 